\title{
A IMPORTÂNCIA DO VISUAL MERCHANDISING NA PERCEPÇÃO DOS CONSUMIDORES
}

\section{THE IMPORTANCE OF VISUAL MERCHANDISING IN THE CONSUMERS PERCEPTION}

\section{RESUMO}

Este trabalho teve como objetivo analisar a importância dos elementos de visual merchandising (VM) na percepção dos consumidores, identificando se existem diferenças significativas quando os consumidores são segmentados por sexo, idade, escolaridade e faixa de renda. Para alcançar tal objetivo, realizou-se uma pesquisa de abordagem quantitativa, aplicando um questionário a 150 respondentes. A análise dos dados foi feita por meio dos testes estatísticos teste $t$ de Student e ANOVA One-Way. Os resultados encontrados indicaram que os elementos de VM que mais apresentaram diferenças entre os grupos foram vitrine e cores, sendo tidos como mais importantes para mulheres, que têm até 25 anos, possuem ensino fundamental e recebem até um salário-mínimo ou entre um e dois salários. Alguns elementos, como fachada, acessibilidade, provadores e exposição dos produtos, não obtiveram diferenças significativas entre os grupos.

Palavras-chave: Visual Merchandising. Percepção do Consumidor. Varejo.

Karen Batista

karen.batista@hotmail.com Mestranda em Administração no Programa de Pós-graduação em Administração da Universidade Federal de Sergipe PROPADM/UFS. Universidade Federal de Sergipe - SE - BR.

Maria Andrea Rocha Escobar escobar.ufs@gmail.com Doutora em Administração e Turismo pela Universidade do Vale do Itajai - UNIVALI. Professora Adjunta da Universidade Federal de Sergipe - SE - BR.

\section{ABSTRACT}

This work aimed to analyze the importance of the elements of visual merchandising (VM) in consumer perception, identifying if there are significant differences when consumers are segmented by sex, age, schooling level and income range. To achieve this goal a quantitative approach was carried out, applying a questionnaire to a total of 150 respondents. Data analysis was performed using Student $t$ test and ANOVA One-Way statistical tests. The results showed that the elements of VM that presented the most differences between the groups were showcase and color, being considered as more important for women, who are up to 25 years of age, have basic education, and receive up to a minimum wage or between one and two salaries. Some elements such as façade, accessibility, dressing rooms and product exposition did not obtain significant differences between the groups.

Keywords: Visual Merchandising. Consumer Perception. Retail. 


\section{INTRODUÇÃO}

O varejo brasileiro, considerado um dos setores mais dinâmicos da economia, tem passado por diversas transformações nas últimas décadas. Entre os fatores que provocaram tais transformações, destacam-se as mudanças no comportamento do consumidor, o surgimento de novos formatos de varejo (como o e-commerce e social commerce), e a abertura de mercado que ocorreu por intermédio da globalização, que possibilitou a entrada de grandes varejistas estrangeiros no Brasil (LAS CASAS; GARCIA, 2007). Diante da grande competitividade existente nesse setor e das mudanças que ocorrem constantemente, as empresas precisam, cada vez mais, destacar-se dos concorrentes. Portanto, para permanecerem nesse mercado, é necessário buscar a diferenciação.

Nesse sentido, os varejistas têm aproveitado o próprio espaço interno da loja como meio para obter diferencial competitivo, transformando-o em um ambiente convidativo e estimulante. No setor de serviços, essa diferenciação é ainda mais importante devido ao fato de os serviços serem intangíveis, ou seja, não podem ser tocados ou sentidos. Dessa forma, o ambiente da loja é a parte mais tangível e influencia a percepção do consumidor acerca do serviço ofertado e, por isso, tem recebido maior atenção por parte das empresas.

As técnicas de Visual Merchandising (VM) constituem uma ferramenta utilizada por varejistas para compor uma apresentação e uma atmosfera da loja, utilizando a iluminação, as cores, o layout, o som, o aroma, o design, a comunicação visual e as vitrines, explorando os cinco sentidos humanos. Ele prepara o ambiente para receber o cliente e deixá-lo à vontade na loja, pois, quanto mais à vontade ele estiver, maior será a chance de realizar a compra. Porém, o visual merchandising não é importante apenas para incrementar as vendas, ele também ajuda a criar, na mente do consumidor, uma percepção positiva do estabelecimento.

De acordo com os dados da pesquisa " $\mathrm{A}$ hora certa de ativar o shopper", realizada pela
Nielsen (2015), cerca de 70\% das decisões de compra são tomadas no ponto de venda. A propaganda pode até criar o desejo de consumo, mas a decisão de compra acontece no momento em que o consumidor entra em contato com o produto no ponto de venda. Por isso o visual merchandising é considerado uma das mídias mais eficazes, pois é a única que conta com os três elementos que compõem a venda: o consumidor, o produto e o dinheiro (BLESSA, 2011).

Com produtos cada vez menos diferenciados e lojas quase idênticas, é necessária a utilização do visual merchandising para transformar o ponto de venda em um ambiente que provoque sensações positivas no consumidor, tornando a experiência de compra um momento único. Um ambiente agradável deixa o cliente mais confortável e, consequentemente, aumenta a possibilidade da compra ser efetivada.

Blessa (2011, p. 31) destaca a importância do visual merchandising, quando afirma que "é preciso criar um design diferenciado e agradável de loja para promover visitas e muitas vendas." A atmosfera da loja deve ser trabalhada para estimular o cliente a passar o maior tempo possível na loja, para que, assim, compre mais. Nesse sentido, o visual merchandising contribui para transformar o ambiente da loja de modo que ele influencie as decisões de compra do consumidor.

Por meio das técnicas de visual merchandising, é possível transmitir a imagem de loja que o varejista deseja. Portanto, o visual merchandising pode ser utilizado para fortalecer a imagem da empresa, pois ele possibilita ao cliente ter experiências prazerosas, o que afeta, diretamente, sua percepção de qualidade acerca do produto/serviço consumido, além de destacá-la dos seus concorrentes. No ponto de venda, o cliente pode ter maior contato com o produto, pode ver, tocar, sentir, e isso deve ser explorado como um diferencial pelo varejista.

Assim, o tema em questão é relevante por se tratar de importante ferramenta de diferenciação e vantagem competitiva para as empresas de varejo e de serviços. Contudo, para que o visual merchandising alcance seus obje- 
tivos, é necessário verificar se seus elementos são considerados importantes na percepção dos consumidores, caso contrário, os esforços de marketing não alcançarão seus objetivos.

Partindo disso, busca-se compreender a importância do visual merchandising na percepção dos consumidores. Dessa forma, esse trabalho teve como objetivo analisar a importância dos elementos de visual merchandising na percepção dos consumidores, identificando se existem diferenças significativas quando os consumidores são segmentados por sexo, idade, escolaridade e faixa de renda.

Este artigo está dividido em cinco seções: a primeira é a introdução; em seguida, são apresentados os principais conceitos sobre visual merchandising, bem como os elementos que o compõem; a terceira seção apresenta os procedimentos metodológicos adotados para alcançar o objetivo proposto; na quarta seção, são apresentados e discutidos os resultados obtidos na pesquisa; e, por fim, são apresentadas as considerações finais do estudo.

\section{REVISÃO DA LITERATURA}

Este capítulo discorrerá sobre os principais conceitos teóricos disponíveis na literatura acerca do tema em questão, a fim de construir um embasamento para alcançar o objetivo proposto. Para tanto, inicialmente, trata-se do visual merchandising, e, em seguida, são apresentados os elementos que compõem a atmosfera de loja.

\subsection{VISUAL MERCHANDISING}

Visual merchandising, segundo Blessa (2011), é a técnica de trabalhar o ambiente da loja, criando identidade por meio do design, da arquitetura e da decoração, que tem o objetivo de aclimatar, motivar e induzir o consumidor à compra. Assim, com essa técnica, é possível ambientar os produtos e a loja. Bernardino et al. (2008) conceituam o visual merchandising como a combinação de todos os estímulos visuais presentes no ambiente da loja, abrangen- do tudo o que o consumidor percebe. Segundo os mesmos autores, o visual merchandising vai além do sentido da visão para tornar-se um conceito de percepção.

Apesar do nome, o visual merchandising não envolve apenas a visão, ele procura estimular todos os sentidos humanos: a visão pode ser estimulada pelas cores e pelas luzes; o olfato, pelos aromas e suas associações emocionais; o paladar, por meio de degustações de produtos; a audição pode ser despertada por uma música de que o cliente goste; e o tato pode ser explorado, permitindo ao consumidor tocar o produto. Com as técnicas de visual merchandising, o varejista pode criar um ambiente agradável, que estimule os cinco sentidos dos clientes, que desperte, no consumidor, sentimentos positivos sobre sua loja e transforme o momento da compra em uma experiência prazerosa.

De acordo com Bernardino et al. (2008, p. 130), o visual merchandising é o instrumento estratégico que possibilita ao varejista "construir a sua imagem e oferecer uma experiência de compra que atenda às expectativas do consumidor." A função do visual merchandising é atrair os consumidores para o interior da loja por meio de uma vitrine impactante, do layout da loja e da disposição dos produtos, estimularem a permanência dos clientes no ponto de venda, para motivá-los à compra e proporcionar uma experiência positiva, garantindo, desse modo, que o consumidor retorne à loja (MORGAN, 2011).

Além disso, a apresentação dos produtos de forma mais atraente visualmente contribui para formar a imagem global da loja. Um varejista de desconto pode usar expositores simples para apresentar a mercadoria, enquanto uma loja que pretende transmitir uma imagem mais sofisticada pode utilizar mesas de exposição, prateleiras e estantes elegantes para exibir seus produtos. Dessa forma, é importante que a estratégia de visual merchandising combine com todos os outros elementos que constituem a loja, para transmitir uma imagem harmoniosa (MALHOTRA; EBSTER; GARAUS, 2013).

$O$ visual merchandising, também, pode ser utilizado para afirmar a identidade da empre- 
sa. Conforme Sackrider, Guidé e Hervé (2009), os elementos de visual merchandising, como a apresentação da loja, as vitrines, a atmosfera e a apresentação dos produtos, a decoração e a comunicação visual da empresa contribuem para dar personalidade à empresa e constituir sua imagem. O ponto de venda representa, então, uma ferramenta para formar na mente dos clientes uma imagem positiva da loja, a partir da utilização desses elementos combinados, de maneira coerente.

Do ponto de vista estético, o visual merchandising cria uma impressão favorável da loja, simplifica o processo de compra do consumidor, e o induz a comprar mais e a retornar à loja, além de transformá-la em um local estimulante para a compra. Do ponto de vista técnico, o visual merchandising contribui para elevar a produtividade da loja, aumentar o giro do estoque e, consequentemente, aumentar as vendas (BERNARDINO et al., 2008).

Por meio das técnicas de visual merchandising, o varejista pode construir uma atmosfera que transmita ao consumidor o que a loja é, o tipo de produto que vende, criando um ambiente agradável e sugestivo para a compra. A seguir, serão apresentados os elementos de visual merchandising que podem ser utilizados na construção da atmosfera da loja.

\subsubsection{Apresentação externa da loja}

A apresentação externa da loja provoca o primeiro impacto no consumidor e sinaliza o tipo de atmosfera que encontrará em seu interior. Ela provoca um forte impacto na imagem da loja, pois determina a primeira impressão que o cliente tem dela, influenciando sua percepção sobre a qualidade dos produtos vendidos e sobre o tipo de loja. Os aspectos da apresentação externa da loja devem ser bem trabalhados para atrair o consumidor e estimulá-lo a entrar na loja. Por meio desses aspectos, a loja pode projetar uma imagem, que pode ser sofisticada, popular, conservadora ou de moda jovem, de acordo com o que o varejista pretende (PARENTE, 2007).
De acordo com Parente (2007), na definição da apresentação externa de uma loja, devem ser considerados alguns fatores: a visibilidade da loja é um fator de grande importância, pois, além de atrair consumidores, reforça a lembrança na mente de quem vê a loja. É importante, também, que haja compatibilidade com o ponto, não só na adequação do tamanho da loja ao tamanho do ponto, como também na harmonia com as demais edificações da imediação. A arquitetura da loja deve transmitir uma imagem positiva e comunicar a impressão que o varejista deseja que o cliente tenha em relação à sua loja, e a fachada da loja deve despertar a atenção do consumidor e motivá-lo a entrar.

A entrada da loja deve apresentar uma boa iluminação, piso plano e sem degraus e materiais não escorregadios, para estimular o consumidor a entrar na loja. Blessa (2011, p. 26) destaca algumas das barreiras invisíveis, que desestimulam o consumidor a entrar na loja: má localização; fachada feia ou escura; degraus e obstruções; vitrines desorganizadas; falta de preço nas vitrines.

A sinalização, também, é muito importante na comunicação externa. A placa com identificação ou logomarca do varejista é, geralmente, a primeira sinalização que o consumidor percebe. Seu tamanho, forma, cor e iluminação devem ser adequados para despertar interesse e convidar o consumidor a entrar na loja. A placa também serve para comunicar informações importantes, como o horário de funcionamento da loja, número de telefone, por exemplo. Os totens também ajudam a reforçar a visibilidade da loja e podem indicar sua presença mesmo a uma longa distância (PARENTE, 2007).

\subsubsection{Vitrine}

A vitrine é o reflexo da oferta de produtos, do estilo e do público-alvo que a empresa pretende atingir. Ela contribui para a construção da imagem da loja e é o primeiro ponto de contato entre a empresa e os seus clientes (SACKRIDER; GUIDÉ; HERVÉ, 2009). De acordo com Malhotra, Ebster e Garaus (2013, 
p. 62), a vitrine é "uma das ferramentas de comunicação de marketing menos dispendiosas e mais eficientes que um negócio pode usar." A vitrine é uma importante mídia do ponto de venda, principalmente para pequenos varejistas que não fazem propaganda, e cria uma aproximação entre a empresa e o consumidor.

Uma boa vitrine não é somente capaz de atrair o consumidor para o interior do estabelecimento, como também reforça a imagem da empresa. A vitrine "é a primeira impressão que o cliente terá da loja e, certamente, uma ideia do que irá encontrar lá dentro" (HASCKEL; DEL-VECHIO, 2014, p. 19). Segundo Godoy (2004 apud ZAMBERLAN et al., 2010), a vitrine deve gerar o impulso de compra no consumidor. Ela precisa ser preparada para vender por si só, como se a loja não dependesse de vendedores. Malhotra, Ebster e Garaus (2013) ressaltam que é importante que o varejista tenha uma estratégia clara para a sua vitrine, ele deve escolher o que deseja transmitir por meio dela. Se desejar atrair o maior número de pessoas para a loja, ele deve expor as principais mercadorias acessíveis na vitrine. Se desejar transmitir uma imagem de loja exclusiva, deve focar em mercadorias inovadoras e de alto preço.

Por meio da vitrine, a loja faz uma declaração a respeito do segmento de público que pretende atingir. É necessário, portanto, focar em apenas um segmento, pois ao tentar agradar vários públicos, não se agrada a nenhum. Além disso, as vitrines refletem a imagem e o estilo da loja. Pelo tipo de decoração, é possível até julgar os preços que determinada loja pratica. Em lojas de vestuário, as vitrines são de extrema importância, porque atraem os clientes para dentro da loja. No entanto, é importante tomar cuidado para não expor produtos que não se tenham em estoque, pois a falta de produtos expostos ou disponibilidade de apenas alguns tamanhos frustra o consumidor (BLESSA, 2011).

É fundamental que, na apresentação de uma vitrine, sejam expostos apenas um número limitado de produtos, caso contrário, causará no consumidor, um desconforto visual, pois o excesso de informação causa confusão. Lojas que apresentam muitos produtos na vitrine causam a impressão de lojas de desconto. Ao desenvolver um tema para a decoração de uma vitrine, deve-se assegurar que ele é coerente com os produtos e com a loja. O uso de texto colorido e impactante pode realçar uma vitrine, mas não se pode esperar que o consumidor leia um texto longo em uma vitrine. É melhor utilizar frases curtas, simples e explicativas (BLESSA, 2011; MORGAN, 2011).

O varejista deve estar atento ao tempo de vida útil de uma vitrine, que é curto. Uma vitrine que causa impressão de novidade, com o tempo torna-se cansativa. De modo geral, as vitrines devem ser modificadas a cada duas ou três semanas, mas os produtos expostos podem ser trocados com mais frequência. Em lojas de shopping, onde o movimento é intenso, devem ser trocadas em menor tempo. Lojas que se encontram em ruas residenciais, em que o público é quase sempre o mesmo, a vitrine deve ser trocada semanalmente (ZAMBERLAN et al., 2010). Segundo Malhotra, Ebster e Garaus (2013), os consumidores têm sede de novidade e uma vez atraídos por determinada vitrine, é muito mais difícil atraí-los novamente, no futuro, com a mesma vitrine.

\subsubsection{Design da loja}

Um design diferenciado ajuda na criação de uma atmosfera agradável e na atração de clientes. Segundo Morgan (2011), o principal objetivo do projeto de uma loja é apresentar os produtos da melhor maneira possível por meio de uma combinação de ambiência, funcionalidade e design de interiores convidativo. O design da loja deve apresentar coerência com os produtos vendidos e com o público-alvo da loja. Ao projetar um design de loja, alguns itens devem ser levados em consideração (PARENTE, 2007).

a) paredes: as cores, as texturas e o acabamento das paredes são fatores que contribuem para construir a atmosfera da loja. Lojas mais sofisticadas geralmente dão um acabamento mais elaborado para suas paredes, com detalhes 
em relevo e com decorações, ou com revestimento, como papel de parede ou carpete. Já em lojas mais populares, ou que comunicam uma imagem de preço baixo, as paredes levam apenas um revestimento básico de tinta;

b) largura dos corredores: a largura dos corredores está associada ao grau de conforto que a loja oferece aos clientes. Corredores estreitos ficam congestionados e dificultam a locomoção. Consumidores passam mais tempo em uma loja e compram mais quando sentem maior comodidade para locomover-se, ou seja, quando os corredores são mais amplos;

c) pisos: os pisos devem conferir segurança e comodidade aos consumidores, como também, reforçar a imagem do varejista. Pisos de lojas mais sofisticadas são revestidos de produtos mais nobres, como madeira ou carpetes. Já lojas mais populares utilizam pisos mais simples de cimento ou cerâmica;

d) temperatura: como, na maioria das regiões e dos meses do ano no Brasil, faz calor, os varejistas têm investido, cada vez mais, em oferecer lojas climatizadas, com ar condicionado para atrair e reter consumidores por mais tempo dentro da loja, transformando o ambiente em um lugar agradável para a compra;

e) provadores: nas lojas de confecções, os provadores são um importante elemento que contribuem para a formação da imagem e devem ser considerados ao se projetar uma loja. Em lojas mais populares, os provadores são menores, simples e com pouca privacidade. Nas lojas de padrão mais alto, os provadores são maiores, mais confortáveis e bem equipados.

\subsubsection{Layout da loja}

De acordo com Parente (2007), ao entrar na loja, o consumidor deseja obter, rapidamente, informações sobre os produtos disponíveis, preços e outras informações necessárias para facilitar sua decisão de compra. Um layout adequado, no qual o cliente possa movimentar-se com comodidade, arrumação lógica dos produtos, etiquetas legíveis, são importantes na composição de um ambiente agradável. O layout da loja é muito importante para os gerentes de varejo e tem uma enorme influência sobre os clientes. As lojas devem criar um layout que minimize o desperdício de movimento no processo de compra (MERUGU; VADDADI, 2017).

O layout da loja corresponde à disposição de divisórias, pilares, provadores ou qualquer outro elemento fixo que interfira na circulação dos consumidores (BERNARDINO et al., 2008). O layout deve proporcionar um fluxo suave de tráfego de consumidores, uma atmosfera prazerosa e um uso eficiente do espaço. Nas decisões de layout, o varejista determina quais produtos ocuparão as áreas preferenciais e quais ficarão nas áreas de menor circulação. É preciso levar em consideração que algumas áreas da loja têm maior visibilidade, e mais valor que outras. Os produtos localizados nas partes da frente da loja são mais visíveis do que os localizados no fundo, por exemplo. Por meio de um layout adequado, o varejista pode estimular o consumidor a circular por diversas áreas da loja (PARENTE, 2007).

Para Levy e Weitz (2000 apud ZAMBERLAN et al., 2010), o layout ideal para o consumidor é aquele que torna o processo de compra mais confortável, divertido, estimulante, em que os consumidores possam localizar os produtos e escolhê-los facilmente. Para o empresário, o layout ideal é aquele que, além de contribuir para a satisfação dos clientes, incentiva-os a movimentarem-se pela loja, para que comprem mais que o planejado, aumentando, assim, o volume de vendas.

Por meio do layout, procura-se proporcionar conforto aos consumidores, assegurando um fluxo eficiente, em que o consumidor tenha espaço suficiente para movimentar-se, sem esbarrar em produtos, expositores ou em outras 
pessoas. O layout influencia a percepção do cliente em relação ao estilo e à imagem que ele tem da loja, como afirma Parente (2007). A circulação dos clientes é um fator fundamental ao elaborar um layout de uma loja. O cliente deve ser orientado pelo layout, para seguir um trajeto pré-definido pelo varejista. Para otimizar o espaço da loja, o consumidor deve ser conduzido de um produto a outro, por meio de corredores e expositores (MORGAN, 2011).

\subsubsection{Comunicação Visual}

Segundo Blessa (2011, p. 33), os elementos que constituem a comunicação visual de uma loja são "letreiros indicativos, placas decorativas, banners com fotos de produtos, pôsteres com fotos de pessoas (perfil dos consumidores), efeitos teatrais fixos (decoração de fundo), decorações sazonais (balões, coelhos de páscoa, papai Noel, namorados)", entre outros.

A comunicação visual no ponto de venda é muito importante, visto que, "durante a compra, a visão é o primeiro sentido humano responsável pelo processo de escolha, pois é o primeiro estímulo que faz o cérebro reagir na direção do produto" (BLESSA, 2011, p. 13). A pesquisa feita pela Veronis, Shler \& Assoc., que avaliou os cinco sentidos humanos na percepção, constatou que os seres humanos aprendem $1 \%$ pelo paladar, $1,5 \%$ pelo tato, $3,5 \%$ pelo olfato, $11 \%$ pela audição e $83 \%$ pela visão (op. cit.).

A comunicação visual de uma loja serve, tanto para orientar os consumidores em seu processo de compra, como também para reforçar a atmosfera criada pelo varejista. A sinalização do produto e do seu preço é um dos elementos que encorajam o consumidor a comprá-lo, e, por isso, devem estar sempre visíveis. Em lojas mais populares que reforçam o preço baixo como vantagem competitiva, as etiquetas de preço são destacadas. As lojas mais elegantes, ao contrário, utilizam sinalização mais discreta dos preços, para ajudar a incrementar a atmosfera de sofisticação (PARENTE, 2007).

O propósito de uma sinalização é chamar a atenção e informar, portanto, deve proporcio- nar ao consumidor facilidade e rapidez para compreender a mensagem (BLESSA, 2011). De acordo Sarmento (2008 apud ZAMBERLAN et al., 2010), a comunicação visual proporciona benefícios tanto para o consumidor, quanto para o varejista. Para o consumidor, a comunicação visual no ponto de venda oferece informações necessárias para sua decisão de compra, pois simplifica o processo de separar os produtos similares. Já para o varejista, traz um melhor resultado nas vendas, pois a comunicação visual no ponto de venda estimula o consumidor a comprar e aumenta o tempo de permanência na loja.

\subsubsection{Iluminação}

Os consumidores são, muitas vezes, atraídos por alguns pontos de venda que se destacam pelo visual bonito e agradável, e que possuem um poder de envolver e convidá-los a entrar e a conhecer. Já outros aparentam ser frios ou quentes demais, o que acaba afastando o desejo de permanecer em seu interior, ou, até mesmo, de entrar neles. Um dos aspectos que pode atrair ou repelir os clientes é a iluminação (ZAMBERLAN et al., 2010).

De acordo com Blessa (2011, p. 34):

A boa iluminação é responsável por clarear o ambiente, destacar mercadorias, decorar espaços especiais e acompanhar o estilo e a personalidade da loja. [...] A iluminação destaca partes atrativas da loja e pode disfarçar as partes visualmente desagradáveis e que não podem ser mudadas. [...] Lojas escuras ou as que "economizam luz" criam uma atmosfera pouco atrativa, desestimulando os clientes a entrar. [...] Toda a loja deve ser clara, mesmo durante a luz do dia. O tipo de iluminação também precisa ser estudado com atenção, para não modificar as cores reais das mercadorias. [...] Lâmpadas focais que dão destaque dirigido às mercadorias na vitrine valorizam os produtos e direcionam o olhar do cliente. 
A iluminação exerce forte influência no ambiente da loja, podendo até afetar o volume de vendas. Estudos indicam que o movimento cai quando a iluminação diminui ou aumenta e quando a iluminação volta ao normal. A claridade é, psicologicamente, mais atraente. Lojas mais claras são percebidas como mais agradáveis, mais limpas e convidam o cliente a permanecer nela por mais tempo, o que é um dos principais objetivos dos varejistas. A iluminação também exerce considerável influência sobre o comportamento humano.

Um ambiente bem iluminado pode aumentar as compras por impulso, pois aumenta o nível de estimulação de uma pessoa, o que, por sua vez, aumentará a propensão de fazer compras por impulso (PARENTE, 2007; MALHOTRA; EBSTER; GARAUS, 2013). Conforme Roble (2005 apud ZAMBERLAN et al., 2010) tão importante quanto o produto exposto, é como ele e o ambiente onde se encontra é iluminado. Utilizar apenas lâmpadas frias não é indicado, porque a luz branca não destaca os produtos, não valoriza suas cores e torna o ambiente impessoal. Também não é indicado utilizar apenas lâmpadas quentes, pois faz que o ambiente aparente seja abafado e desconfortável para o consumidor, espantando-o. Para que a iluminação do ambiente seja eficiente $\mathrm{e}$ agradável, deve apresentar um equilíbrio entre lâmpadas frias e quentes: para a iluminação geral, é melhor utilizar as lâmpadas frias que consomem menos e iluminam áreas maiores; para destacar e valorizar produtos específicos, são melhores as lâmpadas quentes.

\subsubsection{Cores}

As cores desempenham um papel importante na ambientação de uma loja. Cores fortes provocam um impacto diferente das cores suaves. As cores podem ser classificadas em quentes, como vermelho, laranja e amarelo, e frias, como azul, violeta e verde. As cores quentes aparentam chamar mais atenção; portanto, são mais adequadas para a parte externa da loja, para atrair os clientes. Elas comunicam uma atmosfera calorosa, informal e confortável. Já as cores frias proporcionam um ambiente de tranquilidade e são adequadas para situações de compra que exigem um maior tempo de escolha, comunicando um sentimento de formalismo e racionalidade (PARENTE, 2007).

As cores são importantes na construção da imagem de varejo, devido a seus significados simbólicos. As associações de cores são influenciadas pela cultura. A mesma cor pode ter significados diferentes em culturas diferentes. Além disso, as associações de cores diferem entre os vários públicos-alvo, como, homens versus mulheres, adolescentes versus consumidores mais velhos (MALHOTRA; EBSTER; GARAUS, 2013).

Outro fator a ser considerado é que nem sempre a reação do indivíduo aos estímulos cromáticos é uniforme, variando muito de pessoa para pessoa. Cada pessoa pode ter suas preferências, que também pode mudar de acordo com a moda, com a situação econômica ou, até mesmo, com dificuldades existenciais (MENDES; LUCIAN; ABREU, 2019). Segundo Hagtvedt e Brasel (2016), as preferências dos consumidores por cores ou tonalidades de cor podem ser determinantes no processo de compra.

Para Blessa (2011), as combinações de cores devem atrair o público-alvo e destacar os produtos. As crianças são atraídas por cores primárias (vermelho, azul e amarelo); os adolescentes são atraídos por cores fortes e quentes; os esportistas, por cores vivas; as compradoras de lingerie, por tons suaves; os homens executivos são atraídos por cores apagadas, como cinza e azul-marinho. Em lojas de confecção, é interessante que a cor da moda ou da estação esteja presente, para criar, no consumidor, um desejo de estar também na moda e comprar o produto.

As pessoas também reagem às cores com certas respostas biológicas automáticas. Cabe ao varejista decidir o sentimento que deseja despertar no consumidor, e qual a cor adequada para isso. Em geral, cores quentes provocam estimulação, enquanto as frias causam um sentimento de paz e relaxamento. A cor vermelha é a mais ativadora e estimula a compra por im- 
pulso. Ao contrário, a cor verde deve ser evitada se o varejista deseja estimular a compra por impulso. O verde é mais adequado para situações, como a espera em filas, porque ajuda a diminuir a ansiedade do consumidor. Se a intenção é criar uma atitude positiva em relação à loja, o azul é mais indicado. Em restaurantes exclusivos e joalherias de alto nível, é recomendável utilizar a cor azul, que evoca sentimentos agradáveis nos consumidores e cria uma atmosfera sofisticada (MALHOTRA; EBSTER; GARAUS, 2013).

\subsubsection{Aromas}

Dos cinco sentidos humanos, o olfato é o que mais influência as emoções, visto que as terminações nervosas que conectam o nariz ao cérebro estão diretamente ligadas ao sistema límbico, que é o responsável pelas reações emocionais imediatas, mesmo que de forma inconsciente. As memórias ligadas aos aromas são intensas e permanecem por mais tempo do que as visuais. Investir em essências exclusivas para perfumar uma loja é uma forma de fixar-se na mente dos consumidores, que associarão as características do ambiente da loja às características do aroma que está no ar. É importante que o aroma da loja seja personalizado, que se identifique com o produto, com o público-alvo e com a imagem da loja (MALHOTRA; EBSTER; GARAUS, 2013; ZAMBERLAN et al., 2010).

Como os aromas evocam emoções nos consumidores, eles influenciam na percepção da atmosfera da loja. Em uma padaria, o cheiro do pão recém-assado estimula o apetite e, portanto, a compra de alimentos. Em uma loja de cosméticos, o aroma dos perfumes serve para atrair os consumidores. Aromas agradáveis reforçam a atmosfera e a imagem da loja, mas os aromas desagradáveis causam uma má impressão da loja nos consumidores. Devem-se evitar os processos de limpeza inadequados, instalações sanitárias defeituosas, umidade excessiva e pouca ventilação, pois proporcionam odores que comprometem a imagem da loja (PARENTE, 2007).

Os aromas podem melhorar o humor dos consumidores, que ficarão mais dispostos a comprar. Um ambiente perfumado provoca no cliente uma sensação de bem-estar e faz que ele permaneça na loja por mais tempo. A avaliação que o cliente faz da loja aromatizada é mais positiva do que em um ambiente não perfumado. Os perfumes provocam fortes respostas emocionais no consumidor, que pode sentir-se mais relaxado, mais animado, ou nostálgico. Os produtos são avaliados mais positivamente em um ambiente aromatizado que combine com o tipo da loja. Independente do perfume usado, o nível de intensidade é importante. Utilizar um aroma muito intenso pode irritar os consumidores. Por outro lado, um perfume menos intenso não evocará nenhuma estimulação no consumidor. $\mathrm{O}$ ideal é que a maioria dos consumidores não perceba o aroma conscientemente quando entram na loja, mas quando perguntada, percebam-no (MALHOTRA; EBSTER; GARAUS, 2013).

\subsubsection{Música}

Assim como os outros elementos, a música pode acrescentar ou depreciar a atmosfera da loja. A música é um elemento que pode ser facilmente trocado e ajustado conforme o período. Os varejistas têm utilizado diversos tipos de músicas em diferentes horários para estimular o comportamento de compra do consumidor. Pela manhã, quando os consumidores de terceira idade preferem fazer suas compras, as músicas devem ser suaves e calmas. Na hora do almoço, em que muitas pessoas fazem compras rápidas, o ritmo pode ser mais acelerado. À tarde, que é o horário preferido pelas donas de casa, deve-se optar por músicas mais atuais, porém, leves. Entre as 17 e 19 horas, o ritmo deve ser mais acelerado, para que as compras sejam feitas rapidamente, evitando filas nos caixas (BLESSA, 2011).

Uma das metas de um ambiente de varejo é induzir os consumidores a ficarem mais tempo dentro da loja, para que tenham mais contato com os produtos que ela oferece, o que, por sua vez, resultará em taxas de compras mais altas. A música pode ser uma ferramenta para fazer 
os consumidores permanecerem mais tempo em uma loja. Estudos indicam que as vendas aumentaram em até $38 \%$ quando a música era lenta em vez de rápida. Os varejistas, também, podem influenciar a percepção do preço com a música. Música clássica transmite aos consumidores uma imagem de exclusividade e alto preço. Já músicas populares transmitem a imagem de preços mais baixos (MALHOTRA; EBSTER; GARAUS, 2013).

É importante ressaltar que não se trata apenas de colocar som ambiente no PDV, deve-se escolher, cuidadosamente, a música mais adequada ao público-alvo da empresa e a seus objetivos. Sintonizar em uma emissora de rádio é arriscado, pois expõe os clientes e funcionários aos ritmos, notícias e comentários da emissora, que podem não ser adequados para a empresa. Além disso, corre-se o risco de o consumidor ouvir anúncios dos concorrentes (ZAMBERLAN et al., 2010). De acordo com Blessa (2011), devem ser evitadas, também, músicas muito agitadas, do tipo "pagode" ou "rock pesado", pois esse estilo de música pode inibir e irritar os consumidores, encurtando o seu tempo de compra.

O segredo para uma boa ambientação está na congruência dos elementos que constituem a atmosfera e o visual merchandising de uma loja. Os elementos ambientais devem combinar com o produto vendido na loja. Uma loja que vende chocolates, por exemplo, pode utilizar aroma de chocolate para criar um ambiente prazeroso. Todos os elementos ambientais também devem combinar bem entre si. Música, iluminação, cores e aromas devem agir em conjunto para formar uma atmosfera global coerente (MALHOTRA EBSTER; GARAUS, 2013). Dessa forma, podem ser resumidos os elementos de visual merchandising da seguinte maneira:
Quadro 1 - Elementos do Visual Merchandising (VM)

\begin{tabular}{|c|c|}
\hline Categorias & Elementos de VM \\
\hline \multirow{4}{*}{ Apresentação } & Fachada \\
\cline { 2 - 2 } Externa da Loja & Acessibilidade \\
\cline { 2 - 2 } & Localização \\
\cline { 2 - 2 } & Vitrine \\
\hline \multirow{4}{*}{ Design } & Estrutura Física \\
\cline { 2 - 2 } & Organização \\
\cline { 2 - 2 } & Decoração \\
\cline { 2 - 2 } & Temperatura \\
\hline \multirow{4}{*}{ Layout } & Provadores \\
\cline { 2 - 2 } & Espaço entre os corredores \\
\cline { 2 - 2 } & Espaço para descanso \\
\hline Comunicação & Exposição dos produtos \\
\cline { 2 - 2 } Visual & Visualização dos preços \\
\hline \multirow{3}{*}{ Atmosfera da loja } & Iluminação \\
\cline { 2 - 2 } & Cores \\
\cline { 2 - 2 } & Aromas \\
\cline { 2 - 2 } & Música \\
\hline
\end{tabular}

Fonte: elaboração própria (2019).

Para avaliar se a utilização desses elementos está adequada, é necessário conhecer a importância que os consumidores dão aos elementos de visual merchandising, e assim, trabalhá-los da melhor maneira. Dessa forma, esse trabalho buscou analisar a importância dos elementos de visual merchandising na percepção dos consumidores, identificando se existem diferenças significativas quando os consumidores são segmentados por sexo, idade, escolaridade e faixa de renda.

Com relação às diferenças de percepção entre os sexos, as mulheres conseguem captar "coisas que os homens nem chegam a registrar. [...] as mulheres possuem uma habilidade sensorial mais oculta. Elas conseguem ler variações sutis em tom de voz, expressão facial, gestos e linguagem corporal - o que lhes dá uma espécie de raio x emocional." (BARLETTA, 2006, p. 74). Já os homens tendem a perceber registrar apenas o essencial (ABREU et al., 2010). Nesse sentido, acredita-se que existem diferenças entre os sexos em perceber os elementos de visual 
merchandising como importantes. Portanto, elaborou-se a seguinte hipótese:

- $\mathrm{H}_{1}$ - Existem diferenças significativas na importância que os consumidores dão aos elementos de visual merchandising de uma loja, quando esses estão segmentados por sexo.

Conforme aponta a literatura, as variáveis socioeconômicas influenciam no comportamento do consumidor. Para Kotler e Keller (2006, p. 179), "as decisões dos compradores são influenciadas por características pessoais, como idade, estágio no ciclo de vida, ocupação, circunstâncias econômicas, personalidade, autoimagem, estilo de vida e valores." Nesse sentido, optou-se por testar também as hipóteses com relação à faixa etária, escolaridade e faixa de renda, a fim de identificar se existem diferenças significativas na percepção sobre a importância dos elementos de visual merchandising nesses segmentos. Assim, foram elaboradas as seguintes hipóteses:

- $\mathrm{H}_{2}$ : Existem diferenças significativas na importância que os consumidores dão aos elementos de visual merchandising de uma loja, quando esses estão segmentados por faixa etária.

- $\mathrm{H}_{3}$ : Existem diferenças significativas na importância que os consumidores dão aos elementos de visual merchandising de uma loja, quando esses estão segmentados por escolaridade.

- $\mathrm{H}_{4}$ : Existem diferenças significativas na importância que os consumidores dão aos elementos de visual merchandising de uma loja, quando esses estão segmentados por faixa de renda.

A fim de analisar tal importância, foram adotados os procedimentos metodológicos na condução dessa pesquisa, que serão apresentados a seguir.

\section{PROCEDIMENTOS ME- TODOLÓGICOS}

Esta pesquisa é caracterizada como exploratória e descritiva. É considerada explora- tória porque visa explorar o tema em questão, para obter maior conhecimento sobre ele, e tem como objetivo "familiarizar-se com o fenômeno ou obter nova percepção dele e descobrir novas ideias. A pesquisa exploratória realiza descrições precisas da situação e quer descobrir as relações existentes entre os elementos componentes da mesma" (CERVO; BERVIAN, 2002, p. 69).

É também caracterizada como descritiva, pois visa descrever a importância do visual merchandising na percepção dos consumidores. A pesquisa descritiva tem como propósito descrever as características de determinada população ou identificar possíveis relações entre variáveis (GIL, 2010). Segundo Richardson et al. (2008, p. 71), a pesquisa descritiva propõe-se a "descobrir as características de um fenômeno como tal. Nesse sentido, são considerados como objeto de estudo uma situação específica, um grupo ou um indivíduo".

Quanto ao método de abordagem, nesta pesquisa, foi utilizado o método quantitativo. A pesquisa quantitativa apresenta metodologia "que procura quantificar os dados e, geralmente, aplica alguma forma de análise estatística." (MALHOTRA, 2012, p. 111). Como instrumento de coleta de dados, foi elaborado um questionário com 22 questões, que contemplavam variáveis socioeconômicas, como sexo, faixa etária, escolaridade e faixa de renda, e questões relacionadas aos elementos de visual merchandising apresentados anteriormente na revisão de literatura.

Para mensuração das respostas, foi utilizada uma escala Likert de cinco pontos, em que os respondentes deveriam marcar o grau de importância que davam aos elementos de visual merchandising, sendo o número 1 nenhuma importância e o número 5 muita importância. A coleta de dados ocorreu via internet, por meio da plataforma Formulários Google. A coleta ocorreu entre maio e junho de 2018. No total, foram obtidos 153 respondentes, e, após a exclusão de sujeitos outiliers multivariados, totalizaram 150 respondentes, que compuseram a amostra desse estudo, caracterizada como não 
probabilística e por acessibilidade. Os dados coletados foram tratados e analisados no software estatístico SPSS v. 20. Os testes estatísticos realizados foram o teste $t$ de Student $\mathrm{e}$ ANOVA One-Way. A seguir, serão apresentados os resultados e a discussão.

\section{RESULTADOS E DISCUSSÃO}

Com relação à caracterização da amostra desta pesquisa, verificou-se que $68,7 \%$ desta foi composta por mulheres, enquanto $31,3 \%$ eram homens. Quanto à idade, $50 \%$ dos respondentes têm até 25 anos, $28 \%$ têm entre 26 e 35 anos, e $22 \%$ dos respondentes têm entre 36 e 45 anos. No que diz respeito à escolaridade dos respondentes, $24 \%$ possuem o ensino fundamental, $43,3 \%$ possuem o ensino médio, $17,3 \%$ possuem graduação e $15,3 \%$ pós-graduação. Quanto à renda individual mensal dos respondentes, verificou-se que $44 \%$ recebem até um salário mínimo, 22\% recebem entre um e dois salários mínimos, $18 \%$ recebem entre dois e três salários mínimos, e $16 \%$ recebem mais de três salários.

Com relação à primeira hipótese, "Existem diferenças significativas na importância que os consumidores dão aos elementos de visual merchandising de uma loja, quando esses estão segmentados por sexo", os resultados podem ser observados na tabela 1 a seguir.

Tabela 1 - Teste $t$ de Student Elementos do VM x Sexo

\begin{tabular}{|c|c|c|c|c|}
\hline Elemento do VM & $\mathbf{t}$ & Significância & Sexo & Média \\
\hline \multirow{2}{*}{ Vitrine } & \multirow{2}{*}{2,281} & \multirow{2}{*}{$\mathrm{p}=0,024$} & Homens & 4,489 \\
\hline & & & Mulheres & 4,748 \\
\hline \multirow{2}{*}{ Estrutura física } & \multirow{2}{*}{2,045} & \multirow{2}{*}{$p=0,045$} & Homens & 4,596 \\
\hline & & & Mulheres & 4,796 \\
\hline \multirow{2}{*}{ Organização } & \multirow{2}{*}{2,580} & \multirow{2}{*}{$\mathrm{p}=0,013$} & Homens & 4,702 \\
\hline & & & Mulheres & 4,932 \\
\hline \multirow{2}{*}{ Decoração } & \multirow{2}{*}{3,523} & \multirow{2}{*}{$\mathrm{p}=0,001$} & Homens & 4,468 \\
\hline & & & Mulheres & 4,835 \\
\hline \multirow{2}{*}{ Temperatura } & \multirow{2}{*}{2,530} & \multirow{2}{*}{$\mathrm{p}=0,014$} & Homens & 4,213 \\
\hline & & & Mulheres & 4,645 \\
\hline \multirow{2}{*}{$\begin{array}{c}\text { Visualização de } \\
\text { preços }\end{array}$} & \multirow{2}{*}{2,040} & \multirow{2}{*}{$p=0,043$} & Homens & 4,426 \\
\hline & & & Mulheres & 4,641 \\
\hline \multirow{2}{*}{ Cores } & \multirow{2}{*}{2,386} & \multirow{2}{*}{$\mathrm{p}=0,020$} & Homens & 4,486 \\
\hline & & & Mulheres & 4,736 \\
\hline \multirow{2}{*}{ Música } & \multirow{2}{*}{3,173} & \multirow{2}{*}{$\mathrm{p}=0,002$} & Homens & 4,277 \\
\hline & & & Mulheres & 4,728 \\
\hline
\end{tabular}

Fonte: elaboração própria (2019).

Para testar essa hipótese, foi realizado o teste $t$ de Student, a fim de identificar se existem diferenças significativas entre os dois grupos, no caso, homens e mulheres. Foram considerados significativos valores $\mathrm{p}<0,05$. Conforme apresenta a Tabela 1, apenas os elementos de VM vitrine, estrutura física, organização, decoração, temperatura, visualização de preços, cores e mú- sica apresentaram significância. Assim, para esses elementos do VM, houve diferenças significativas entre homens e mulheres. Esse resultado pode ser associado ao fato de que as mulheres possuem a habilidade de perceber estímulos sensoriais mais aguçadas que os homens (BARLETTA, 2006). Pode-se observar, na tabela, que as mulheres obtiveram as maiores médias em todos os elementos 
considerados significativos, o que indica que as mulheres dão mais importância a esses elementos de VM, sendo possível aceitar parcialmente $\mathrm{H}_{1}$.

Para o teste das demais hipóteses, foi realizado o teste ANOVA One-Way, que analisa se existem diferenças significativas entre três grupos ou mais. Foram considerados significa- tivos valores $\mathrm{p}<0,05$, e o teste post-hoc realizado foi o DMS. No que diz respeito à hipótese 2, "Existem diferenças significativas na importância que os consumidores dão aos elementos de visual merchandising de uma loja, quando esses estão segmentados por faixa etária", os resultados são apresentados na tabela 2 a seguir.

Tabela 2 - ANOVA One-Way Elementos do VM x Faixa etária

\begin{tabular}{c|c|c|c|c}
\hline Elemento do VM & $\mathbf{F}$ & Significância & Faixa etária & Média \\
\hline \multirow{2}{*}{ Vitrine } & \multirow{2}{*}{11,777} & \multirow{2}{*}{$\mathrm{p}<0,001$} & Até 25 anos & 4,800 \\
\cline { 4 - 5 } & & & De 36 a 45 anos & 4,212 \\
\hline \multirow{2}{*}{ Espaço descanso } & \multirow{2}{*}{6,919} & $\mathrm{p}=0,001$ & De 26 a 35 anos & 4,714 \\
\cline { 4 - 5 } & \multirow{2}{*}{ Cores } & \multirow{2}{*}{8,158} & De 36 a 45 anos & 5,000 \\
\hline \multirow{2}{*}{} & & & Até 25 anos & 4,824 \\
\cline { 4 - 5 } & & & De 36 a 45 anos & 4,424 \\
\hline
\end{tabular}

Fonte: elaboração própria (2019).

Como se pode observar na tabela 2, apenas nos elementos vitrine, espaço de descanso e cores foram encontradas diferenças significativas entre as faixas etárias. Conforme indicam as médias apresentadas na tabela 2 , a vitrine e as cores foram consideradas elementos de VM mais importantes pelos que têm até 25 anos, e o espaço de descanso foi considerado mais importante para os respondentes que têm entre 36 e 45 anos. É interessante observar que as pessoas com mais idade dão importância ao espa- ço de descanso, o que pode ser utilizado como estratégia para o varejista que possui público-alvo dessa faixa etária. Dessa forma, pode-se aceitar apenas parcialmente $\mathrm{H}_{2}$.

Para a terceira hipótese, "Existem diferenças significativas na importância que os consumidores dão aos elementos de visual merchandising de uma loja, quando esses estão segmentados por escolaridade", os resultados são descritos na tabela 3 a seguir.

Tabela 3 - ANOVA One-Way Elementos do VM x Escolaridade

\begin{tabular}{|c|c|c|c|c|}
\hline Elemento do VM & $\mathbf{F}$ & Significância & Escolaridade & Média \\
\hline \multirow{2}{*}{ Localização } & \multirow{2}{*}{6,527} & \multirow{2}{*}{$\mathrm{p}<0,001$} & Fundamental & 5,000 \\
\hline & & & Graduação & 4,500 \\
\hline \multirow{2}{*}{ Vitrine } & \multirow{2}{*}{9,809} & \multirow{2}{*}{$\mathrm{p}<0,001$} & Fundamental & 5,000 \\
\hline & & & Pós-graduação & 4,130 \\
\hline \multirow{2}{*}{ Estrutura Física } & \multirow{2}{*}{4,745} & \multirow{2}{*}{$\mathrm{p}=0,003$} & Fundamental & 4,917 \\
\hline & & & Pós-graduação & 4,565 \\
\hline \multirow{2}{*}{ Tamanho da loja } & \multirow{2}{*}{6,927} & \multirow{2}{*}{$\mathrm{p}<0,001$} & Graduação & 5,000 \\
\hline & & & Pós-graduação & 4,579 \\
\hline \multirow{2}{*}{$\begin{array}{l}\text { Espaço entre os } \\
\text { Corredores }\end{array}$} & \multirow{2}{*}{4,208} & \multirow{2}{*}{$\mathrm{p}=0,007$} & Fundamental & 5,000 \\
\hline & & & Pós-graduação & 4,783 \\
\hline \multirow{2}{*}{ Iluminação } & \multirow{2}{*}{3,446} & \multirow{2}{*}{$\mathrm{p}=, 018$} & Fundamental & 4,917 \\
\hline & & & Médio & 4,708 \\
\hline \multirow{2}{*}{ Cores } & \multirow{2}{*}{4,161} & \multirow{2}{*}{$\mathrm{p}=0,007$} & Fundamental & 4,833 \\
\hline & & & Graduação & 4,385 \\
\hline \multirow{2}{*}{ Aromas } & \multirow{2}{*}{5,373} & \multirow{2}{*}{$\mathrm{p}=0,002$} & Fundamental & 5,000 \\
\hline & & & Pós-graduação & 4,652 \\
\hline
\end{tabular}

Fonte: elaboração própria (2019). 
Conforme demonstra a tabela 3, os elementos localização, vitrine, estrutura física, tamanho da loja, espaço entre os corredores, iluminação, cores e aromas apresentaram diferenças significativas. Os elementos de VM localização, vitrine, estrutura física, espaço entre os corredores, iluminação, cores e aromas foram considerados mais importantes pelos participantes que possuem ensino fundamental, enquanto o elemento tamanho da loja foi con- siderado mais importante pelos que possuem graduação, como se pode observar nas médias apresentadas na tabela 3. Assim, aceita-se parcialmente $\mathrm{a}_{3}$.

Por fim, para o teste da quarta hipótese, "Existem diferenças significativas na importância que os consumidores dão aos elementos de visual merchandising de uma loja, quando esses estão segmentados por faixa de renda", os resultados estão na tabela 4 a seguir.

Tabela 4 - ANOVA One-Way Elementos do VM x Faixa de Renda

\begin{tabular}{|c|c|c|c|c|}
\hline Elemento do VM & $\mathrm{F}$ & Significância & Faixa de Renda & Média \\
\hline \multirow{2}{*}{ Localização } & \multirow{2}{*}{2,651} & \multirow{2}{*}{$\mathrm{p}=0,05$} & Até 1 salário & 4,878 \\
\hline & & & Entre 1 e 2 salários & 4,636 \\
\hline \multirow{2}{*}{ Vitrine } & \multirow{2}{*}{6,866} & \multirow{2}{*}{$\mathrm{p}<0,001$} & Entre 1 e 2 salários & 4,909 \\
\hline & & & Entre 2 e 3 salários & 4,259 \\
\hline \multirow{2}{*}{ Temperatura } & \multirow{2}{*}{9,218} & \multirow{2}{*}{$\mathrm{p}<0,001$} & Até 1 salário & 4,682 \\
\hline & & & Acima de 3 salários & 3,750 \\
\hline \multirow{2}{*}{ Tamanho da loja } & \multirow{2}{*}{4,826} & \multirow{2}{*}{$\mathrm{p}=0,003$} & Entre 2 e 3 salários & 4,974 \\
\hline & & & Acima de 3 salários & 4,625 \\
\hline \multirow{2}{*}{ Espaço descanso } & \multirow{2}{*}{4,437} & \multirow{2}{*}{$\mathrm{p}=0,005$} & Entre 2 e 3 salários & 4,667 \\
\hline & & & Acima de 3 salários & 4,958 \\
\hline \multirow{2}{*}{ Cores } & \multirow{2}{*}{5,166} & \multirow{2}{*}{$\mathrm{p}=0,002$} & Até 1 salário & 4,834 \\
\hline & & & Entre 1 e 2 salários & 4,455 \\
\hline \multirow{2}{*}{ Música } & \multirow{2}{*}{4,802} & \multirow{2}{*}{$p=0,003$} & Até 1 salário & 4,758 \\
\hline & & & Acima de 3 salários & 4,083 \\
\hline
\end{tabular}

Fonte: elaboração própria (2019).

Como apresenta a tabela 4 , apenas os elementos localização, vitrine, temperatura, tamanho da loja, espaço de descanso, cores e música apresentaram diferenças significativas. Os elementos localização, temperatura, cores e música foram considerados mais importantes pelos respondentes que recebem até um salário mínimo; a vitrine pelos que recebem entre um e dois salários mínimos, o tamanho da loja por aqueles que recebem de dois a três salários mínimos e o espaço de descanso pelos que recebem mais de três salários-mínimos, como pode ser observado na tabela 4. $\mathrm{A}_{4}$ pode ser aceita apenas parcialmente.

\section{CONSIDERAÇÕES FINAIS}

Este trabalho teve como objetivo analisar a importância dos elementos de visual merchandising na percepção dos consumidores, identificando se existem diferenças significativas quando os consumidores são segmentados por sexo, idade, escolaridade e faixa de renda. Para alcançar tal objetivo, realizou-se uma pesquisa de abordagem quantitativa, aplicando um questionário a um total de 150 respondentes. A análise dos dados foi feita por meio dos testes estatísticos teste $t$ de Student e ANOVA One-Way.

Os resultados encontrados indicaram que apenas alguns elementos de visual merchandising foram considerados importantes na percepção dos consumidores, levando em consideração as diferenças entre os grupos. Para essa amostra, os elementos de VM que mais apresentaram diferenças entre os grupos fo- 
ram vitrine e cores, sendo tidos como mais importantes para mulheres, que têm até 25 anos, possuem ensino fundamental e recebem até um salário mínimo ou entre um e dois salários. Alguns elementos como fachada, acessibilidade, provadores e exposição dos produtos não obtiveram diferenças significativas entre os grupos.

Algumas implicações gerenciais podem ser extraídas dos dados obtidos nesta pesquisa: deve-se levar em consideração qual o público-alvo do varejista ao projetar um ambiente, visto que, entre os elementos de VM apresentados aqui, alguns são considerados mais importantes por mulheres, pessoas mais jovens e outros são mais importantes para pessoas com mais idade e maior poder aquisitivo. Os gestores devem levar em consideração que é importante desenvolver uma atmosfera de loja agradável, onde o cliente sinta-se bem e que estimule o seu processo de compra, pois, quanto mais tempo o cliente permanecer em uma loja, mais ele comprará. O tempo que ele permanece dentro da loja depende do conforto e do prazer proporcionados pela experiência de compra.

Por fim, ressalta-se, como limitação desse trabalho, o número reduzido dos respondentes, e o fato de a amostra não ser probabilística, não podendo, dessa forma, generalizar os resultados para a população. Como sugestões para futuros trabalhos, pode ser feito um estudo comparativo em duas lojas, avaliando as diferenças entre as percepções dos clientes em uma loja que utiliza bem os elementos de visual merchandising e em outra que não os utiliza. Sugere-se, também, analisar o visual merchandising a fim de identificar o posicionamento pretendido e o percebido pelos clientes, fazendo uma comparação entre a imagem projetada e a imagem percebida.

\section{REFERÊNCIAS}

ABREU, N. et al. Estudo da percepção de gêneros sobre a comunicação em sites na internet. INMR - Innovation \& Management Review, v. 7, n. 2, p. 60-79, 12 ago. 2010.
BARLETTA, M. Marketing para mulheres. Rio de Janeiro: Elsevier, 2006.

BERNARDINO, Eliane de Castro et al. Marketing de varejo. 3. ed. Rio de Janeiro: Editora FGV, 2008.

BLESSA, Regina. Merchandising no ponto-de-venda. 4. ed. 7. São Paulo: Atlas, 2011.

CERVO, Amando Luiz; BERVIAN, Pedro Alcino. Metodologia científica. 5. ed. São Paulo: Prentice Hall, 2002.

GIL, Antônio Carlos. Como elaborar projetos de pesquisa. 5 . ed. São Paulo: Atlas, 2010.

HASCKEL, A. M.; DEL-VECHIO, R. A vitrina como diferencial competitivo: as ações das lojas dos shoppings de atacado do setor têxtil de Brusque. [S.l.: s.n.], 2014.

KOTLER, P.; KELLER, K. L. Administração de Marketing. 12. ed. São Paulo: Pearson Prentice Hall, 2006.

LAS CASAS, Alexandre Luzzi; GARCIA, Maria Tereza. Estratégias de marketing para varejo: inovações e diferenciações estratégicas que fazem a diferença no marketing de varejo. São Paulo: Novatec Editora, 2007.

MALHOTRA, Naresh K. Pesquisa de marketing: uma orientação aplicada. 6. ed. Porto Alegre: Bookman, 2012.

MALHOTRA, Naresh; EBSTER, Claus; GARAUS, Marion. Design de loja e merchandising visual: criando um ambiente que convida a comprar. São Paulo: Saraiva, 2013.

MENDES, I.; LUCIAN, R.; ABREU, N. Sensorial Merchandising: Um Experimento no Varejo de Moda para Inclusão de Consumidores Cegos. REGEPE - Revista de Empreendedorismo e Gestão de Pequenas Empresas, v. 8, n. 1, p. 126-148, 2019. 
MERUGU, Pratima; VADDADI, Krishna Mohan. Visual Merchandising: (um estudo sobre o comportamento de compra impulsiva do consumidor na cidade de Visakhapatnam). Revista Internacional de Ciência e Pesquisa em Tecnologia de Engenharia (IJETSR), v. 4, n. 7, p. 915-927, 2017.

MORGAN, Tony. Visual merchandising: vitrines e interiores comerciais. 2. ed. Barcelona: Editora GG, 2011.

NIELSEN. A Hora certa de ativar o Shopper. [S.l.: s.n.], 2015.

PARENTE, Juracy. Varejo no Brasil: gestão e estratégia. São Paulo: Atlas, 2007.

RICHARDSON, Roberto Jarry et al. Pesquisa social: métodos e técnicas. 3. ed. São Paulo: Atlas, 2008.

SACKRIDER, Françoise; GUIDÉ, Gwenola; HERVÉ, Dominique. Entre vitrinas:

distribuição e visual merchandising na moda. São Paulo: Editora Senac São Paulo, 2009.

ZAMBERLAN, Luciano et al. Gestão Estratégica do ponto de venda: decisões para qualificar a performance no varejo. Ijuí: Ed. Unijuí, 2010. 